\title{
The EU self-surplus puzzle: an indication of VAT fraud?
}

\author{
Martin T. Braml ${ }^{1}$ D . Gabriel J. Felbermayr ${ }^{2}$
}

Accepted: 29 October 2021 / Published online: 22 December 2021

(c) The Author(s) 2021

\begin{abstract}
The world runs a trade surplus with itself: the reported values of exports exceed the reported values of imports. This is logically impossible but a well-known empirical fact. Less well-known is the fact that, in recent years, the EU has a trade surplus with itself that amounts to more than $80 \%$ of the global surplus. In this paper, we show that this EU self-surplus is worth a striking 307 billion Euro in 2018, equaling $1.9 \%$ of the Union's GDP, which persists both in goods and services trade accounts. We further examine discrepancies in goods and services trade accounts at the country and country pair level. These are strongest between neighboring countries and exist for members of the Euro Area as well as non-members. Around the 2004 Eastern Enlargement, the EU self-surplus quadrupled. Our estimations suggest that Cyprus, Ireland, Luxembourg, and Sweden are EU Members with the most inaccurate statistical regimes. We observe systematic biases which unlikely root in random measurement error. By contrast, we suspect that a large fraction of the EU's self-surplus puzzle seems related to fraud in value added tax (VAT). VAT exemptions for exporters provide strong incentives for the over-declaration of true export values. The resulting loss in tax income could amount to as much as 64 billion Euro per year.
\end{abstract}

Keywords Missing trade $\cdot$ VAT fraud $\cdot$ Statistical discrepancies $\cdot$ Current accounts

JEL Classification F36 · F32 · F24 · H26

Martin T. Braml

martin.braml@wto.org

Gabriel J. Felbermayr

gabriel.felbermayr@wifo.ac.at

1 World Trade Organization, Ifo Institute - Leibniz Institute for Economic Research at the University of Munich, Munich, Germany

2 Austrian Institute for Economic Research, Vienna University of Economics and Business, Vienna, Austria 


\section{Introduction}

The world runs a current account surplus with itself (Gros, 2017): a logical impossibility that must result from measurement error or from-possibly fraudulent-misreporting. This global current account surplus is mainly driven by the trade balance, and not by primary income statistics, which are known to suffer from measurement error. This fact - that we refer to as the world's self-surplus-has prompted Krugman (2010) to develop a humorous theory of "interstellar trade" that could be at the root of the global surplus.

Less well known, the European Union has been running massive trade surpluses with itself over years, i.e., exports from EU Member States to other EU Member States exceed the value of imports as recorded by the importer. This self-surplus amounts to 307 bn Euro in 2018, or 1.9\% of the Union's GDP. The EU's self-surplus is almost as big (86\%) as the global-surplus of 357 bn Euro (422 bn USD) in $2018 .{ }^{1}$ It is larger than the frequently criticized current account surplus of Germany ${ }^{2}$, and surpasses the combined GDP of the eight smallest EU Member States. It is therefore too big to be lightheartedly discarded as an irrelevant if amusing statistical artefact. As we argue, this self-surplus follows non-random patterns and may therefore unveil systematic biases. We suspect that the discrepancy may result from massive fraud in value added tax (VAT) declarations, which would amount to up to 64 billion Euro in a worst case scenario. In principle, such fraud would involve an over-declaration of export figures to save VAT for domestic sales. This is possible due to the destination principle in the European VAT system. Hence, firms face a sizeable and direct incentive to mis-report domestic transactions as exports. On the aggregate level, this may yield a credit-bias in intra-European Balance of Payments (BoP) data and can consistently explain the EU's trade self-surplus.

Recently, probably due to increasing international economic tensions, current account (CA) statistics have attracted unusual attention both from policy makers as well as researchers. For instance, there is substantial uncertainty about whether the EU has run a bilateral CA surplus or a deficit with the United States over the past decade. In times of trade conflicts, the absence of a definite answer is troublesome; see Braml and Felbermayr (2019) for an illustration and tentative interpretation of transatlantic facts. The underlying problem, however, is broader: International transaction data are of poor quality, due to negligence, strategic government manipulation, and fraud. This obviously sets limits for meaningful evidence-based research and policy making and, probably even worse, allows fraudsters hiding their illegal activities.

\footnotetext{
${ }^{1}$ Note that this does not imply that the EU's self-surplus "explains" $86 \%$ of the global total, as the sum of all excess surplus could exceed $100 \%$ if at least one other economy runs an excess deficit. Hence, the attribution of a "gross contribution" to a "net figure" needs to be interpreted with caution.

${ }^{2}$ In the Euro Area, the large surpluses of Germany and the Netherlands vis-à-vis other Euro members have provoked difficult political discussions; see Gros (2012); Bonatti and Fracasso (2013); Kollmann et al. (2015).
} 
To the best of our knowledge, ours is the first paper that offers a systematic analysis and interpretation of the EU's self-surplus. ${ }^{3}$

We provide novel evidence by (i) describing the magnitudes and dynamics of the discrepancies in the intra-EU current account, by (ii) decomposing the self-surplus according to the sub-accounts in the current account, by (iii) investigating the contributions of single EU Member States, and by (iv) the interpretation of our findings based on forensic accounting methods. For example, we show that goods and services trade contribute almost equally to the observed discrepancy. This allows us to rule out such explanations that are specific to only either of the two sorts of trade, e.g., CIF-FOB differentials in the case of goods trade. Given the persistence of the discrepancy, random statistical noise can unlikely account for the observed patterns. Hence, we raise the cui bono-who benefits?-question and argue, later in this paper, that VAT fraud is a plausible explanation for the significant credit-bias that is prevalent in European current account statistics.

For very good reasons, economists usually deem bilateral current account balances irrelevant from a macroeconomic perspective (Feenstra et al., 1999; Mankiw, 2018). However, they are of great importance for bilateral economic relations, in particular in the context of trade conflicts, currency unions, and external imbalances. For a deeper understanding of these self-surpluses as well as to explore potential mechanisms that drive it, this paper not only examines aggregated figures but focuses in greater detail on country and country pair specific discrepancies.

Discrepancies in so-called mirror data are statistical artefacts prevalent in many international data with dyadic dimension. ${ }^{4}$ In principle, any market transaction involves the documentation of corresponding values by buyer and seller. After correct summation, balances must necessarily mirror each other: All countries' exports are equal to all countries' imports; this is a mechanical accounting process and holds true by definition. However, in reality, perfectly corresponding mirror data are the exception rather than the rule. Frankel (1978) discusses potential reasons for the worldwide current account deficit in the 1960s and 1970s.

In the early 2000s, the global debit-bias has turned into a credit-bias, meaning that surpluses exceed deficits. Helbling and Terrones (2009) suggest that time lags in international transportation might lead to lagged recording of imports relative to exports; in a world of rapidly growing trade, global surpluses would be a necessary consequence. According to this explanation, lengthy shipment processes and high growth rates distort trade figures. This bias should even revert, when global trade shrinks.

Academic literature has emphasized the link between missing trade and export restrictions: Fisman and Wei (2009) measure the smuggling of art as bilateral

\footnotetext{
3 The mere fact has been highlighted by Eurostat; see Eurostat 2018, accessed on April 10, 2019.

4 To be clear, in the following analysis, we do not focus on bilateral CA imbalances but discrepancies. Imbalances occur if country A and B exchange different amounts of goods and services, which is true for most of the country pair relationships worldwide. Statistical discrepancies occur if a transaction between $\mathrm{A}$ and $\mathrm{B}$ is recorded differently by sender (exporter) and receiver (importer). In other contexts, current account discrepancies describe the statistical difference between the current and the financial account.
} 
discrepancy in trade figures and Vézina (2015) shows that missing exports frequently result from resource export restrictions. Both studies illustrate that discrepancies at the country level correlate with corruption indexes. ${ }^{5}$ Since export restrictions lead to an under-declaration of the true export values, the opposite mechanism could explain the EU's self-surplus: import restrictions would materialize in excess trade surpluses. However, no relevant import restrictions vindicating missing trade of more than 300 bn Euro annually are known in the very case of intra-EU trade, one of the world's most liberalized cross-border economic zone.

Considering the geographical proximity of EU Member States and the resulting possibility for land transportation, the relative weak economic growth, as well as the fact that services trade is equally affected, leads us to assume that other reasons must lie at the heart of the observed discrepancies. Ferrantino et al. (2012) investigate discrepancies in goods trade between the USA and China and link them to VAT fraud and tariff evasion. As tariff evasion can be ruled out for transactions within the EU customs union, our interpretation focuses on VAT fraud. In a nutshell, we argue that firms over-report the true value of their exports to receive a VAT rebate for goods that are sold domestically. The resulting export statistics are overblown and fail to match corresponding import figures.

The remainder of this paper is structured as follows: first, Sect. 2 discusses relevant conceptual issues and, second, reports the main finding: an empirical stocktaking of the EU and Euro Area self-surpluses. Third, it shows which Member State pairs exhibit the most severe discrepancies and identifies the countries that are most likely "responsible" for the discrepancy of a given pair. Section 3 provides a broad discussion of our descriptive findings, thereby turning to VAT fraud as an explanation for the observed discrepancies. Moreover, it estimates the potential revenue shortfalls and outlines a concept for an electronic clearing procedure that would tackle VAT fraud by the over-declaration of exports. Section 4 summarizes our main findings and concludes.

\section{Documenting the EU self-surplus puzzle}

\subsection{Current account data}

Providing a full picture of the entire current account distortions would require information on all its items: goods trade, services trade, primary income, and secondary income. ${ }^{6}$ In a world without reporting issues — where mirror data match perfectlythe following two accounting identities must hold:

\footnotetext{
${ }^{5}$ Illicit trade has also been a determinant for social outcomes such as violence in the case of illegal mahogany trade in Brazil (Chimeli \& Soares, 2017).

6 Primary income refers to receipts and payments of employee compensation paid to non-resident workers as well as investment income (receipts and payments on direct investment, portfolio investment, other investments, and receipts on reserve assets). Secondary income designates current transfers between residents and non-residents, i.e., payments without quid pro quo such as remittances, international cooperation payments, or cross-border fines. Cf. International (2019).
} 
1 All sub-accounts of the intra-EU current account sum to zero.

2 The aggregate intra-EU current account sums to zero.

Identity 1 is self-evident. If it holds, Identity 2 holds as well. Even if Identity 1 is violated, Identity 2 can still hold. This could be the consequence of so-called demarcation problems. ${ }^{7}$ Such demarcation problems emerge, for instance, with "servitization": this means that an increasing share of services content embodied in manufacturing exports caused by, amongst others, related software, design, financing, or maintenance tasks makes a clear-cut differentiation between goods and service trade difficult. ${ }^{8}$ Also, some transactions may misleadingly appear in primary income accounts rather than in services trade accounts. This can be the case when countries do not provide services associated with intangible assets directly but through tax havens. Typically, such demarcation issues cancel out after aggregation. ${ }^{9}$

For the purpose of the present analysis, we rely on balance of payments (BoP) data provided by Eurostat only. ${ }^{10}$ This rules out methodological differences in data compilation or differences in the interpretation of the Balance of Payments Manual 6 (International, 2019) by reporting countries. ${ }^{11}$ Please note that for Malta data are either not recorded or not published. All values are denoted in Euro. We apply the term "discrepancy" to refer to corresponding import-export statistics which fail to match each other. Aggregate discrepancies are also referred to as self-surpluses or self-deficits, respectively. Unless not specified otherwise, imports and exports include the sum of goods and services trade. In contrast to primary income accounts, which are not accessible, we also observe sizeable discrepancies in secondary income accounts (which are typically considered to be the least important current account item). In 2018, they amount to 98 bn Euro. Secondary income consists of government transactions and private donations (aid, remittances) and is therefore quite different from cross-border trade (that is conducted predominantly firm-to-firm). Hence, it does not come as a surprise that its statistical recording suffers from severe shortcomings. For our objective- the identification and quantification of VAT fraud-discrepancies in the secondary income account are if at all of only little relevance. Hence we do not further investigate them.

\subsection{The evolution of the EU's trade self-surplus}

First of all, we present the overall trade balance for the EU and the Euro Area with themselves. For this purpose, we sum up trade balances of all EU (Euro Area) Member States vis-à-vis all EU (Euro Area) Member States.

\footnotetext{
7 The different treatment of the same transaction by statistics authorities in different countries.

${ }^{8}$ For a broad overview, cf. Baines et al. (2009).

9 On the substitutability of services trade and primary income, cf. the discussion part in Braml and Felbermayr (2019).

10 The main data source for CA figures is the series $b o p_{c} 6_{q}$ in the version from November 2019.

11 Find here the IMF BPM6: www.imf.org/external/pubs/ft/bop/2007/bopman6.htm.
} 
Figure 1 shows that both the EU and the Euro Area run substantial trade self-surpluses; evidently, Identity 1 has been violated for the past 12 years. In 2018, the total self-surpluses (goods and services) amount to 307 and 126 bn Euro, respectively. These self-surpluses equal 1.9 and $1.1 \%$ of the respective nominal GDP. The mere size of the intra-EU trade surplus is stunning: In absolute numbers, it is more than the combined GDP of the EU's 8 smallest economies. ${ }^{12}$ Dynamics of the shown discrepancies reveal that these self-surpluses are persistent over time: over 12 years of observation, the EU and the Euro Area ran surpluses that cumulatively amount to 3 and 1.6 trillion Euro. While for the Euro Area, the total discrepancy fluctuates between 0.5 and $1 \%$ of GDP for almost one decade, the EU-wide self-surplus has increased and now reaches levels close to 2\%. From 2013 onward, both the EU and the Euro Area exhibit a strong growth in the services trade self-surplus. When it comes to the EU, $46 \%$ of the total discrepancy is due to services trade. In the case of the Euro Area, this share amounts to $31 \%$ in 2018. Any major difference between the EU and the Euro Area can plausibly be attributed to the UK to a large extent. ${ }^{13}$ This issue has statistically been resolved by Brexit but may still be prevalent economically. Overall, these discrepancies can hardly result from random measurement errors; otherwise, one would expect the time series to be stationary with mean zero.

The reported discrepancies have also changed relative to the gross trade volume: Figure A-1 shows the dynamic of the self-surpluses relative to the aggregated BoP credit positions. For the EU, the self-surplus in goods has decreased from 9.5 to $5.5 \%$ in 2011 and moves sideways since. For the Euro Area, the level has decreased from $7.5 \%$ in 2015 to $4.9 \%$ in 2018 . For both the EU and the Euro Area, self-surpluses in service trade show an upwards trend over time with an increase from 4.4 to $11.3 \%$ and from 2.6 to $6.1 \%$, respectively.

As initially proposed, discrepancies in opposite directions because of demarcation issues would cancel. If that was the case, one balance would have to show a self-surplus and the other a self-deficit. This is not the case: for both the EU and the Euro Area, the total discrepancy of the net exports is almost perfectly equal to the total of discrepancies of the goods balance and the services balance. ${ }^{14}$

As mentioned before, not just the EU but the entire world runs a substantial trade self-surplus. This discrepancy amounts to 422 bn USD, which equals $0.5 \%$ of global output (or, equivalently, about $1.7 \%$ of world exports) in 2018 , and is only slightly higher than the EU's total trade self-surplus of 363 bn USD (307 bn EUR). Figure 2 tracks the evolution of the global trade self-surplus, the EU's trade self-surplus as well as the global current account discrepancy, which consists by and large of global trade surpluses. The diagram shows that the global trade self-surplus was negative before 2004 and has increased since then, mostly in lockstep with the EU's own

\footnotetext{
12 According to Eurostat's nominal GDP figures for 2018.

13 As the UK accounted for the lion's share of non-Euro Area intera-EU trade when it still was part of the EU. Our previous analysis has shown that UK figures are one of the main reasons for substantial service trade discrepancies of the EU with the USA (Braml \& Felbermayr, 2019). Thus, the UK statistical recording of service trade not only contributes to EU-US current account discrepancies, but also distorts intra-EU BoP figures quite substantially.

14 Net exports are constructed as the difference between exports and imports.
} 
self-surplus. Thus, the global surplus does not appear to result from interstellar trade (Krugman 2010) but rather, misreporting within the EU seems to play an important role. $^{15}$

Strikingly, the global trade deficit started growing in 1993 and turned into a surplus in the late 1990s. During the preceding decades, it always has been a global deficit. The year 1993 is also the starting date of the EU Single Market, which has facilitated intra-European trade substantially (Felbermayr et al., 2018). In 2004, the EU Eastern enlargement has created the world's second largest internal market. Unfortunately, comprehensive data series that would allow calculating the EU selfsurplus back to 1993 are not available. Between 1999 and 2003, the EU self-surplus has remained very stable. Later, coinciding with the EU Eastern enlargement, it has quadrupled. Arguably, establishing the Single Market has simplified VAT procedures in intra-EU trade. Other ancillary achievements such as the Schengen Agreement or the creation of the Euro Area have fostered intra-EU trade on top of that; unintentionally, it may have facilitated the chance for VAT fraud, too. ${ }^{16}$

\subsection{Dissecting the discrepancies}

The aim of the following sections is to shift the focus of the analysis to the country and country pair level. More specifically, we are interested in identifying country pairs that cause particularly large discrepancies. One can plausibly argue that the quality of institutions, the nature of national tax systems, and even geography should play a role in explaining discrepancies caused by fraudulent behavior, in particular by VAT evasion. Therefore, this section serves as the empirical foundation of the interpretation outlined in Sect. 3.

We draw on Eurostat data on bilateral trade flows (goods and services) for the year 2018. ${ }^{17}$ Considering all 28 EU Member States, we have a maximum of 756 $(28 \times 27)$ observations per BoP item. ${ }^{18}$ The Eurostat BoP data yield intra-EU goods trade exports (credit) totaling 2874 bn Euro. This accounts for $82 \%$ of intra-EU exports recorded by Eurostat trade statistics (Comext). ${ }^{19}$ It becomes apparent immediately that the coverage of EU BoP data is in need of improvement. The sensitivity analysis in Sect. 2.6 provides a more detailed comparison of BoP and foreign trade statistics data.

\footnotetext{
15 As discussed in footnote 1, since both the EU self-surplus and the global surplus are net magnitudes, one cannot strictly say that the EU surplus 'explains' the global one.

16 Indeed, in its Foreign Trade Statistics (FTS), Eurostat has been reporting a self-surplus of the EU since 1993 as well.

17 As our only data source we use Eurostat $\operatorname{bop}_{c} 6_{q}$. Due to data limitations, we cannot provide detailed sector specific results but focus on aggregate bilateral BoP items (goods trade account and services trade account) between EU Member States.

18 After excluding missings-those trade flows for which neither party provides information-we lose 35 observations. For some additional trade flows, we miss data that are not available from both parties. Data reported by Malta and Spain are not available.

19 Eurostat records total intra-EU trade based on export figures of 3525 bn Euro in 2018.
} 
(a) $\mathrm{EU}$

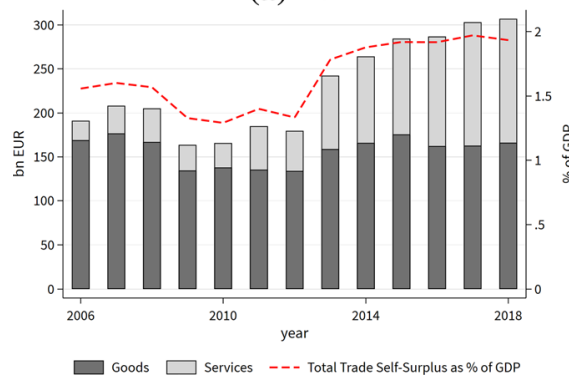

(b) Euro Area

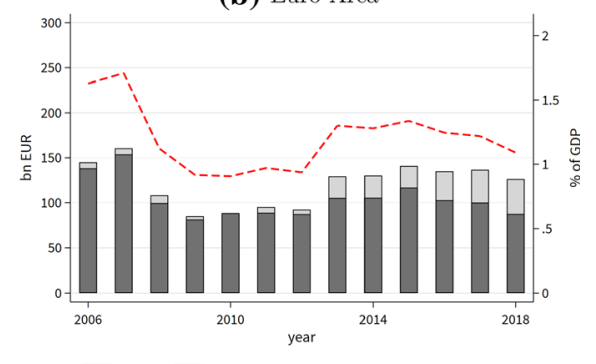

$\square$ Goods $\square$ Services --- Total Trade Self-Surplus as \% of GDP

Fig. 1 EU and Euro area trade self-surpluses, bn EUR and \% of GDP. Source: Data from Eurostat 2019; own calculations. Note: Left scale in bn Euro refers to the bars, right scale in \% of nominal GDP refers to the dashed line. Figures show balances of the goods and services trade BoP accounts.

Our preferred measure for bilateral discrepancies takes credit and debit positions into account. The vectors $X_{i j}$ and $M_{i j}$ are reported by country $i$, the vectors $X_{j i}$ and $M_{j i}$ by country $j .{ }^{20}$ In the case of perfectly matching mirror data, $X_{i j}$ should equal $M_{j i}$ and $M_{i j}$ should equal $X_{j i}$. Let $\mathcal{E}$ denote the set of all EU Member States. Ideally, we should observe

$$
\sum_{j \in \mathcal{E}} \sum_{i \in \mathcal{E}} X_{i j}=\sum_{j \in \mathcal{E}} \sum_{i \in \mathcal{E}} M_{j i}
$$

However, bilateral flows do not match perfectly in the data so that $X_{i j} \neq M_{j i}$ and $M_{i j} \neq X_{j i}$. Consequently, the equality above fails to hold. We may define the discrepancy $\Delta_{\mathcal{E}}$ such that

$$
\Delta_{\mathcal{E}} \equiv \sum_{j \in \mathcal{E}} \sum_{i \in \mathcal{E}}\left(X_{i j}-M_{j i}\right)=\sum_{j \in \mathcal{E}} \sum_{i \in \mathcal{E}} \Delta_{i j}
$$

where we define the absolute bilateral reporting discrepancy as $\Delta_{i j} \equiv X_{i j}-M_{j i}$. Empirically, we observe $\Delta_{\mathcal{E}}>0$. This can be due to systematic over-reporting of $X_{i j}$ or under-reporting of $M_{j i}{ }^{21}$ As the "true" size of the trade flows between $i$ and $j$ is unknown, we cannot distinguish between the two sources of misreporting. Both are possible. If we knew the true value, which assumptions could we make about the structure of the measurement error?

Assuming errors are random and multiplicative, the number of elements in $\mathcal{E}$ growing very large, would lead to $E\left(\Delta_{\mathcal{E}}\right) \rightarrow 0$. As we will show empirically, this is not true. So, errors in fact are non-random. In the following, the discrepancy in a pair is expressed in relative terms as

$$
\delta_{i j}=\frac{2 \Delta_{i j}}{X_{i j}+M_{j i}} .
$$

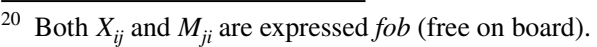

${ }^{21}$ In principle, even both can be misreported but to different degrees. 


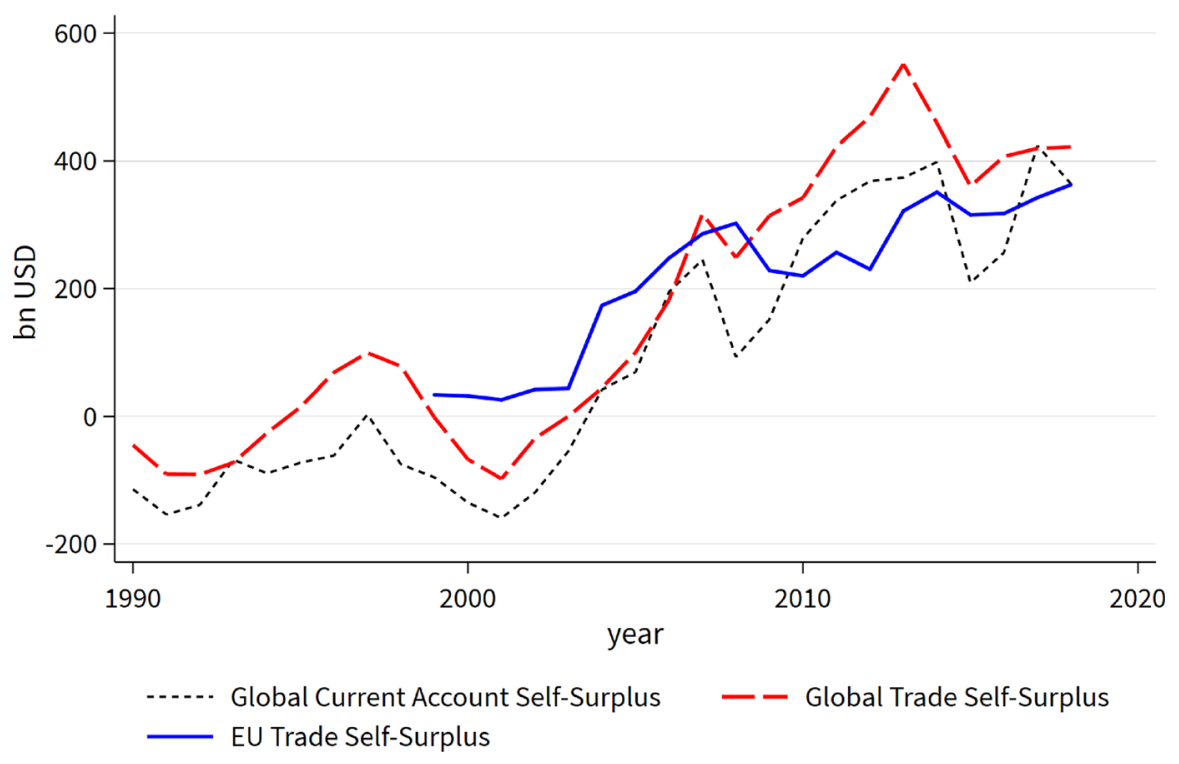

Fig. 2 The EU self-surplus in the global context, bn USD. Source: IMF 2019. World Bank 2019. Eurostat 2019; own calculations. Note: Comprehensive EU data before 1999 are not available. The global current account and trade self-surpluses refer to the sum over all current account and trade balances, respectively. Global figures might include missing values.

For the sake of convenience, this equation is pre-multiplied with $100 \%$. Table 1 shows summary statistics for the observed discrepancies in bilateral BoP data for the year 2018. Figure A-2 illustrates the underlying distribution graphically. Positive means and medians confirm what we know from aggregate data: the presence of a credit/export bias. For goods trade, $50 \%$ of the flows are outside a discrepancy range between -10 and $18 \%$. For services trade, the same is true for a range between -18 and $46 \%$.

\subsection{Country analysis}

This section scrutinizes which countries appear to have the largest reporting biases. The identification of Member States who play a major role in causing the observed discrepancies is of great interest. Due to the dyadic dimension of the problem, a definite identification is difficult to achieve. As an approximation to this problem, we calculate average country level discrepancies:

$$
\delta_{i}=\frac{1}{n} \sum_{j \in \mathcal{E}} \delta_{i j} \quad \text { and } \quad \delta_{j}=\frac{1}{n} \sum_{j \in \mathcal{E}} \delta_{i j}
$$

where $\delta_{i}$ denotes the mean discrepancy for country $i$ being the exporter, $\delta_{j}$ denotes the mean discrepancy for country $j$ being the importer, and $n$ measures the number 
of trade partners (i.e., the cardinality of the set $\mathcal{E}$ ). Table 2 shows mean discrepancies per country based on Eq. 4 for goods and services separately.

Member States with the largest export biases (in percent) are Luxembourg (41), Bulgaria (29), and Greece (28). Germany, Europe's largest exporter, reports on average $10 \%$ higher goods exports than its respective importers. ${ }^{22}$ The Netherlands (0.3), Czechia (-3), and France $(-3.3)$ are those Member States with the lowest discrepancies in their goods exports. Sweden (- 65), Cyprus (- 62), and Ireland (- 20) display a severe tendency toward a substantial under-reporting of their exports.

Discrepancies in services accounts are on average larger than in goods accounts: the average absolute discrepancy is $26 \%$ (18\% in goods). Over-reporting goods exports goes along with over-reporting services exports. The two figures are significantly positively correlated (corr $=0.62)$. The most accurate reporting is performed, again, by France (2.3) and the Netherlands (-0.8), the largest inaccuracies are observed for Cyprus $(-80)$ and Luxembourg (63).

Table 2 indicates that economically smaller EU Member States are more likely to exhibit larger discrepancies. Indeed, absolute values of discrepancies decrease in mean trade volume: a doubling of trade volume lowers absolute discrepancies by 4.9 (goods) and 3.7 (services) percentage points. This does not come as a surprise: scale economies might also apply to statistical recording, and statistical offices might allocate resources to prioritize tackling larger trade flows. Scatter plots in Figs. A-3 and A-4 show the relationship between trade volume and discrepancy.

\subsection{Country pair analysis}

This subsection explores which country pairs are particularly prone to bilateral discrepancies. Additionally, we investigate whether neighboring countries display notably higher discrepancies - another finding that would support our hypothesis that VAT fraud plays a role in solving the self-surplus puzzle. We begin by defining the mean country pair discrepancy as

$$
\zeta_{i j} \equiv \frac{1}{2}\left(\left|\delta_{i j}\right|+\left|\delta_{j i}\right|\right),
$$

which is a symmetric measure in the sense that $\zeta_{i j}=\zeta_{j i}$. Hence, we base our analysis on 378 unique country pairs. ${ }^{23}$ We average absolute values of flow discrepancies since positive and negative discrepancies could otherwise net out. Country pair

\footnotetext{
22 As either party of a given transaction can be the source of misreporting, figures provided in Table 2 need to be interpreted cautiously. For instance, Bulgaria shows an export over-reporting bias of $29 \%$ on average, one of the highest observed. This bias can either be caused by 'false' reporting of exports by Bulgaria, or 'false' reporting of imports by all other countries (or, most likely, a combination of the two). Assuming all countries but Bulgaria misreport their imports, the Romanian export bias, for instance, should resemble the Bulgarian figure. In fact, it is only about half of it. The same holds true for all other individual countries. Thus, the observed variation in mean export discrepancies across EU Member States is a simple and qualified indicator for country specific reporting biases.

23 Considering all 28 EU Member States, the number of pairs is given by $28 \times 27 / 2$.
} 
Table 1 Summary statistics: bilateral discrepancies, 2018, in \%. Source: Data from Eurostat 2019; own calculations

\begin{tabular}{llllllll}
\hline & Min & P-25 & Median & Mean & P-75 & Max & SD \\
\hline Goods trade & -195.1 & -10.2 & 5.4 & 2.3 & 17.5 & 206.7 & 49.4 \\
Services trade & -200.0 & -18.0 & 11.0 & 12.7 & 43.1 & 200.0 & 54.8 \\
\hline
\end{tabular}

The table shows summary statistics for the distribution of discrepancies as defined in Eq. 3

discrepancies of goods and services trade are significantly correlated, the correlation coefficient is 0.28 . Table 3 shows summary statistics of the distribution of country pair discrepancies.

Table A-1 and Table A-2 list the country pairs with the highest average discrepancy for goods trade and services trade. Among the 25 country pairs showing the highest pair discrepancies in goods trade, Sweden and Cyprus are listed 12 and 9 times, respectively. In the services account, Cyprus is part of 11 country pairs. The country pair UK-Luxembourg is particularly striking: according to British data, the service trade volume amounts to 8.2 bn Euro; the same figure, as reported by Luxembourg, stands more than three times as large at 27.3 bn Euro. The corresponding discrepancy totals $108 \%$ of the mean trade volume. Also, the UK's service trade with Denmark worth 11.5 bn Euro (on average) shows a discrepancy of $91 \%$. The trade volume of these two country pair relationships is higher than the combined trade of the other 23 country pairs with exceptionally low reporting quality.

\subsection{Comparison with official trade statistics}

Next, we perform a sensitivity analysis based on an alternative data base. To this end, we use 2018 trade data from the Comext database, "Eurostat's reference database for detailed statistics on international trade in goods." 24 A comparison with services trade figures from another data source would be ideal. However, Eurostat only provides services trade data based on its Balance of Payments data, which obviously makes a comparison obsolete.

According to Comext, the EU (Euro Area) runs a self-surplus amounting to 64 (19) bn Euro in 2018. These numbers are significantly lower than those resulting from the reported Balance of Payments data. In contrast to Balance of Payments data, the foreign trade statistics (FTS) applies a different valuation method for imports and exports: Imports reflect transaction values at the border of the importing economy including cost, insurance, freight (cif); exports are recorded according to transaction values at the border of the exporting economy free on board (fob). Thus, a bias toward higher import than export values is systemically inherent to the FTS data. In contrast to the FTS, BoP statistics only comprise fob recorded data. Logically, one would expect zero bilateral discrepancies in BoP data and systematic

\footnotetext{
${ }^{24}$ For more information see ec.europa.eu/eurostat/web/international-trade-in-goods/data/focus-oncomext.
} 
Table 2 Mean discrepancies per country, 2018, in \%. Source: Data from Eurostat 2019; own calculations

\begin{tabular}{|c|c|c|c|c|}
\hline Country & Goods credit & Services credit & Goods debit & Services debit \\
\hline Austria & 16.7 & 33.1 & 3.3 & 24.4 \\
\hline Belgium & -15.8 & 27.4 & -12.8 & 9.6 \\
\hline Bulgaria & 28.6 & 34.0 & 15.4 & -39.0 \\
\hline Croatia & 25.9 & 11.6 & 5.3 & -42.7 \\
\hline Cyprus & -61.9 & -79.9 & -37.5 & -73.3 \\
\hline Czechia & -2.9 & -4.2 & -14.8 & -28.4 \\
\hline Denmark & 6.4 & 48.9 & 3.2 & 11.5 \\
\hline Estonia & 7.6 & 48.7 & -21.2 & 46.1 \\
\hline Finland & 12.4 & 33.1 & -7.5 & 6.0 \\
\hline France & -3.3 & 2.3 & -3.6 & 9.4 \\
\hline Germany & 9.9 & -7.1 & 11.9 & -17.7 \\
\hline Greece & 28.3 & 44.1 & 32.6 & -2.2 \\
\hline Hungary & 7.0 & 24.8 & 11.3 & 2.5 \\
\hline Ireland & -20.0 & -13.1 & -9.2 & -62.0 \\
\hline Italy & 4.7 & 4.0 & -1.1 & 3.5 \\
\hline Latvia & 10.2 & 10.5 & 9.7 & -39.2 \\
\hline Lithuania & 12.4 & 23.3 & 10.1 & -3.1 \\
\hline Luxembourg & 41.2 & 63.3 & 2.1 & 7.7 \\
\hline Netherlands & 0.3 & -0.8 & -3.1 & -32.4 \\
\hline Poland & 14.2 & 26.2 & 4.6 & 5.7 \\
\hline Portugal & 23.1 & 34.4 & 5.9 & -10.9 \\
\hline Romania & 13.6 & 24.2 & 15.6 & 3.5 \\
\hline Slovakia & 10.1 & 10.0 & 5.1 & -11.0 \\
\hline Slovenia & 23.5 & 53.8 & 23.8 & 8.2 \\
\hline Sweden & -65.3 & -2.6 & -55.5 & -22.4 \\
\hline UK & -8.1 & -17.4 & -8.5 & -62.4 \\
\hline
\end{tabular}

Columns 1 and 2 show the average discrepancy in bilateral trade for the respective country being an exporter. Columns 3 and 4 show the average discrepancy in bilateral trade for the respective country being an importer. Discrepancies are defined as in Eq. 4. All values refer only to BoP positions vis-à-vis EU Member States. No data are available for Malta and Spain

import surpluses in FTS data due to cif-fob differentials. Both are evidently not the case, and a sizable export-bias is prevalent even in European FTS. This provides additional evidence for a systematic pattern of over-reported exports within the EU. ${ }^{25}$

Aside from these differences in absolute numbers, Comext data strongly support our previous findings in qualitative terms. These data display a very similar distribution of discrepancies, and they allow replicating the pattern of average

\footnotetext{
${ }^{25}$ Cf. Dimitrov (2004), a Eurostat publication, for more details on methodological differences between BoP and FTS.
} 
Table 3 Summary statistics: country pair discrepancies, 2018 Source: Data from Eurostat 2019; own calculations

\begin{tabular}{lcrlllll}
\hline & Min & P-25 & Median & Mean & P-75 & Max & SD \\
\hline Goods trade & 0.0 & 3.2 & 14.5 & 32.3 & 34.6 & 204.6 & 43.7 \\
Services trade & 0.0 & 12.8 & 30.5 & 40.4 & 55.3 & 200.0 & 37.8 \\
\hline
\end{tabular}

The table shows summary statistics for the distribution of country pair discrepancies as defined in Eq. 5

country discrepancies that we find in Sect. 2.4 as well as the same negative relationship between trade volume and discrepancies. ${ }^{26}$ Again, Cyprus, Ireland and the UK show strong under-reporting biases. Malta, whose BoP data are not available, seems to have the most inaccurate data. For Luxembourg - at odds with the previously detected strong export-bias-a severe import-bias becomes visible. Germany shows the lowest discrepancies according to the FTS data. The country pair analysis yields similar results as shown above: ${ }^{27}$ among the 25 country pairs with the most inaccurate data, Cyprus appears six times; Malta even 11 times.

All our findings remain absolutely robust when choosing 2017 as a reference year. ${ }^{28}$ This is true both for BoP as well as Comext data. Hence, we are confident that the discrepancies shown above result from a systematic pattern that we discuss next. We have provided evidence that identifies country level and country pair level patterns in intra-EU Balance of Payments discrepancies for goods and services trade. In many cases, these discrepancies are disproportionately large and seem to follow recurring patterns. Based on the evidence gathered so far, the next section attempts to unravel the EU's self-surplus puzzle.

\section{Making sense of the self-surplus puzzle}

The findings of the descriptive part highlight that current account data, even within the EU and the Euro Area suffer from very substantial inconsistencies. Recently, the British magazine The Economist postulated that "Rich countries' trade statistics tend to be more reliable than those of emerging economies, where data collection is less developed". ${ }^{29}$ In light of our analysis, one can question this assertion. ${ }^{30}$ Inconsistent data make solid evidence-based economic policy advice very difficult. What is more, it could reflect a much deeper problem: fraud. Since data limitations do not allow a casual identification, our interpretation is tentative. We apply forensic accounting methods and therefore, nota bene, we can neither claim completeness nor ultimate truths. We try to collect evidence for and against our claim.

\footnotetext{
${ }^{26}$ See Figs. A-8 and A-9 as well as Table A-3 in the Online-Appendix.

27 See Table A-4 in the Appendix.

28 For the sake of brevity and in order to avoid duplication, we do not discuss these results.

29 The Economist, November 12, 2011 www.economist.com/finance-and-economics/2011/11/12/expor ts-to-mars, accessed on December 20, 2018.

30 We do not present any comparison between EU BoP data and that of emerging economies, though.
} 
In the following, we first discuss alternative interpretations of discrepancies in goods trade. Second, we move on to services accounts. Supporting our hypothesisthat VAT fraud causes the discrepancies-we follow a forensic accounting approach: We exclude other potential explanations for the observed phenomenon and argue why firms have a strong incentive to over-report true exports. Finally, we estimate the expected fiscal loss due to VAT fraud and outline a brief concept to improve data recording in cross-border trade.

\subsection{Explaining the self-surplus in goods trade}

We have shown that the EU self-surplus in goods trade exhibits a systematic, nonrandom over-reporting bias. Sections 2.4 and 2.5 present evidence for a high degree of variation in the quality of statistical recording across EU Member States and country pairs.

A well-known distortion for EU trade statistics is the so-called Rotterdam Effect. Overseas imports entering the EU in Rotterdam and transiting to other Member States are often recorded as Dutch exports and likewise as an intra-EU import by the counterparty. This leads to inflated trade statistics in bilateral positions with the Netherlands. Discrepancies, however, arise only when these overseas imports are recorded differently by the Netherlands and the country of final destination. ${ }^{31}$ Interestingly, we do not find evidence that the Rotterdam Effect causes discrepancies in intra-EU trade statistics: Dutch accounts on goods trade, both credit and debit, are the most accurate among all EU Member States $(0.3$ and $-3.1 \%$, respectively), which means that they closely match those of their trading partners.

An argument made by Frankel (1978) is that current account discrepancies arise when firms try to circumvent capital controls, for instance, for profit shifting purposes. For intra-EU discrepancies, we can largely rule out this channel, as capital controls within the EU are extremely rare events. ${ }^{32}$ One may suspect that transfer pricing has a distorting effect on intra-EU current account statistics. Even if manipulated transfer prices are used to shift corporate profits, under-priced/ over-priced transactions would not materialize in bilateral discrepancies since accurate BoP figures require correct double-entry bookkeeping, independent of artificially inflated or deflated gross values. Thus, a national trade balance would be distorted by such measures, but discrepancies in bilateral trade statistics are not a consequence thereof.

We believe that value-added tax fraud provides a more convincing explanation for BoP discrepancies. Participants of the Single Market exempt exports from valueadded tax. Effectively, VAT is borne by domestic sales independent of their origin.

\footnotetext{
31 Appendix 3 in the Balance of Payments Manual 6 focuses on special issues for customs unions, economic unions and currency unions. Box A3.I is insightful for the correct recording of transactions between members of such unions, to avoid double counting or artificially inflated trade statistics of economies of consignment.

32 Greece has temporarily introduced capital controls in summer 2015. Cyprus has introduced capital controls between 2013 and 2015. For 2018, the reference time of our analysis, no capital controls in the EU were effective.
} 
When products enter into a foreign EU Member State, VAT is levied in the destination country. That is due to the fact that consumption instead of production is the objective of taxation. Subsequently, the European VAT system is considered an efficient tax, but it is seemingly prone to fraud: if firms declare products as exports which are in fact not exported (or re-imported), they can sell them domestically without remitting VAT to the respective government. The only and most directly concerned beneficiaries of over-stated exports are firms. ${ }^{33}$

Therefore, the European VAT system is evidently prone to tax fraud. To curb such practices, the EU Commission initiated a VAT Action Plan in $2016 .{ }^{34}$ Assessing the damage for European tax payers, the EU Commission has estimated that a single fraud type - the so-called "missing trader"-causes annual VAT revenue shortfalls of 45-53 bn Euro (Fearing et al., 2015). ${ }^{35}$ Fedeli and Forte (2009) describe technical details of VAT fraud systems. ${ }^{36}$ This cross-border fraud type does not necessarily lead to discrepancies in bilateral trade statistics but emphasizes an important issue: the presence of large scale cross-border VAT fraud-presumably because authorities are less capable of identifying cross-border frauds compared to domestic VAT fraud.

The most straightforward way to circumvent VAT for firms is the mere overdeclaration of exports and would, in principle, not involve any other party, neither domestically nor in a cross-border transaction. ${ }^{37}$ In practice, to hide such fraud before tax authorities, several firms who trade on high frequency back and forth are involved. Impeding traceability of transactions, firms located in other EU Member States are usually involved, too. Whether many firms in different countries are involved or not, all such fraud types have one common feature: at some point, a fictitious export is declared and leads both to an unlawful VAT exemption and to a statistical discrepancy in BoP and FTS data. To support our hypothesis, we employ the following OLS regression model:

$$
\zeta_{i j}=\beta_{0}+\beta_{1} \log \left(V_{i j}\right)+X_{i j} \boldsymbol{\mu}+\boldsymbol{v}_{i}+\chi_{j}+\epsilon_{i j}
$$

\footnotetext{
33 Statistical offices, of course, could technically also manipulate data. However, it is questionable why statistical offices should follow such objectives and what their incentives to do so would be.

34 See http://europa.eu/rapid/ press-release_IP-18-3834_en.htm, accessed on December 20, 2018.

35 Please note that these numbers stem from an indirect source. The cited paper is a report for the EU Commission performed by Ernst \& Young. It references an EU Commission VAT gap report, which has originally estimated the cited numbers on VAT revenue shortfalls. The original source was not traceable.

${ }^{36}$ In a nutshell, the "missing trader" practice-in its simplest form-functions as follows: A trader (Firm 2) located in, say, France purchases a product from Firm 1 located in Germany. This cross-border transaction is VAT-exempt. Firm 2 resells the product to a French exporter (Firm 3). For this transaction, VAT is due and must be remitted by Firm 2 to French tax authorities. Due to input tax deduction, Firm 3 reclaims the VAT payment it has made to Firm 2. Firm 3 sells the good across the border back to Firm 1 in Germany. The last transaction is again free of tax. Firm 2 does not remit the VAT, which has been rebated to Firm 3, to French tax authorities. Thereby, French tax payers have rebated VAT to Firm 3 that has never been collected. Firm 2 then "disappears"; such (mailbox) firms are commonly known as "missing trader." Tax fraud experts have named this system "carousel." It should be recalled that firms sometimes are not even aware of being engaged in such carousel-type fraudulent trade.

37 De facto, firms who declare as exports (part of) their domestic sales should also have at least some "real" export business so that they are able to demonstrate existent cross-border business relations before tax authorities.
} 
where $V_{i j}$ denotes the mean trade volume for country pair $i j$. The vector $\mathbf{X}$ includes several country pair specific control variables borrowed from the gravity trade literature: geographic distance, the presence of a common border, common language, shared history as well as differentials in VAT standard rates. ${ }^{38}$ The vectors $v_{i}$ and $\chi_{j}$ denote country fixed effects taking the value one if countries $i$ and $j$ are part of a given country pair. ${ }^{39}$

In light of these empirical results, three findings support our hypothesis: first, our country pair regression analysis suggests that discrepancies in goods trade are $11.6-13 \%$ points higher between neighboring countries (cf. Table 4). ${ }^{40}$ This is an isolated border-effect irrespective of the trade volume (which typically is higher for countries who share a common border). If firms over-declare exports for VAT fraud purposes, they might well likely indicate to authorities the same destinations as of their "true" exports. For many SMEs—given their limited number of export destination markets - these are the neighboring countries. Second, differentials in VAT standard rates lead to higher discrepancies: a one percentage point increase in VAT rate differentials goes along with a $3 \%$ points increase in discrepancies. ${ }^{41}$ Third, we find a significantly positive relationship between country-level BoP discrepancies and domestic VAT compliance gaps estimated by Morrow et al. (2019). ${ }^{42}$ The results are depicted in Fig. A-5. ${ }^{43}$

\subsection{Explaining the self-surplus in services trade}

The above-described export over-declaration incentive exists for services not differently than for goods trade. However, good reasons point in the direction that the

\footnotetext{
${ }^{38}$ Common history means in the case for European countries whether a country pair in the past formed a common state. For example, Croatia and Slovenia both formerly belonged to Yugoslavia. One would expect that quality of statistical recording is better in the presence of shared institutional history.

${ }^{39}$ Cf. Table A-5 for a replication of the results with FTS data. Country fixed effects explain 28-34\% of the total variance. Table A-6 shows all country fixed effect coefficients; they can be interpreted as mean discrepancy in percentage points. These fixed effects constitute an alternative measure for quality of national data recording. Column 3 repeats this exercise with FTS data (cf. Table A-5).

${ }^{40}$ Since we are interested in international trade, the nature of the problem is quite possibly bilateral. In other words: the extent of VAT fraud would not solely depend on either the exporter or the importer, but on their (potentially complex) interaction.

${ }^{41}$ The standard VAT rates in the EU range between 17\% (Luxembourg) and 27\% (Hungary). Note that, while interesting per se, this observation is not needed to rationalize our conjecture. However, high VAT rates do incentivize fraud more strongly than lower rates do. High differentials indicate, of course, that one country with a high VAT rate is involved.

42 This measure is country specific and not directly related to VAT compliance in cross-border transactions. Thus, it is informative about the capability of the government to fight VAT fraud in general. Please note that the insights from such a cross-country analysis based on 26 observations-28 EU Member States minus Malta and Spain, for which bilateral BoP data are not available-are necessarily limited.

${ }^{43}$ We do not detect a statistically significant correlation between average country discrepancies and measures for institutional quality. We employ the Worldwide Governance Index of the World Bank and aggregate the six sub-indexes into one combined index; cf. Figure A-7. Thus, it appears that, in our sample, governments' ability (or willingness) to provide correct BoP data do not depend on institutional quality. Nor we find a significant correlation between average discrepancies and the relative importance of the shadow economy reported by Medina and Schneider (2018). Cf. Figure A-6 .
} 
nature of services trade differs in some respect and that statistical recording is differently conducted. On the one hand, our correlation exercise in Fig. A-5 does not reveal a relationship between VAT compliance gap and services discrepancies. On the other hand, we miss a proxy to account for the quality of statistical recording. Obviously, the less developed statistical recording is, the higher is the chance for successfully embedding illegal or fictitious transactions under the disguise of services trade. For historical reasons, statistical regimes in the EU differ by Member State. And for various reasons, data quality for goods trade are better than for services trade. First, due to the formerly lower economic importance of cross-border service trade, efforts have primarily focused on establishing international standardization for the recording of goods trade. Second, because services are traditionally not subject to import tariffs, governments draw revenue only from the imports of goods. Hence, they always had fiscal interests in high quality statistical recording of international goods trade.

Similarly to discrepancies in services trade between the EU and the USA (Braml \& Felbermayr, 2019), the UK contributes quite substantially to discrepancies in intra-EU services trade: the total EU self-surplus in services amounts to $141 \mathrm{bn}$ Euro. Within the Euro Area, this figure stands at 39 bn Euro only. The British Office for National Statistics (ONS) generates services trade statistics by conducting survey-based partial censuses and national projections, which evidently lead to high discrepancies (Chesson et al., 2018).

However, high average discrepancies for countries with certain relevance for financial services indicate that this sector is particularly prone to statistical misrecording. Table 2 (Column 2 and 4) illustrates that this matters for Cyprus, Ireland, Luxembourg, the Netherlands (only Debits), and the UK. It stands out that these countries display discrepancies for credit and debit accounts that point in the same direction (Cyprus, Ireland, the UK, and the Netherlands exhibit under-reported figures, Luxembourg over-reported figures). Service exports and primary income payments are, to a growing extent, substitutable and can distort BoP sub-accounts. Hence, this issue might be connected to corporate profit shifting. A joint evaluation of services and primary income accounts would be necessary for a final assessment. Due to data limitations, such an undertaking is not possible yet but could be the subject of future research when primary accounts perhaps become available. ${ }^{44}$

Figure 1 shows that the EU's mysterious self-surplus in services has increased five-fold since 2010. This sharp surge can hardly be explained by general recording problems, which would be time-invariant. We therefore suspect another trend to drive this increase: dis-intermediation and e-commerce. Services exports used to be mainly business-to-business transactions in the past. Nowadays, consumers can directly purchase from foreign companies and no intermediator-formerly often a domestic importer-is needed. This is particularly true for cloud, streaming, and software services. When trade mainly consists of high-value business-tobusiness transactions, no systematic credit-bias occurs; but when trade increasingly entails more business-to-consumer transactions, a credit-bias becomes prevalent:

$\overline{44}$ Or by linking services trade discrepancies to corporate profit data bases. 
Table 4 Regression analysis: country pair discrepancies; 2018 cross-section Source: CEPII 2019. Eurostat 2019; own calculations

\begin{tabular}{|c|c|c|c|c|c|c|}
\hline & \multicolumn{3}{|l|}{ Goods } & \multicolumn{3}{|l|}{ Services } \\
\hline & (1) & (2) & (3) & (4) & (5) & (6) \\
\hline \multirow[t]{2}{*}{ log trade } & $-7.05^{* * *}$ & $-5.59^{* * *}$ & $-14.79^{* * *}$ & $-5.83^{* * *}$ & $-4.55^{* * *}$ & -8.19 \\
\hline & $(0.94)$ & $(1.00)$ & $(4.67)$ & $(1.31)$ & $(1.37)$ & $(4.98)$ \\
\hline \multirow[t]{2}{*}{ log distance } & & $14.63^{* * *}$ & -5.83 & & $14.55^{* * *}$ & -3.05 \\
\hline & & $(4.28)$ & (7.49) & & $(4.75)$ & $(8.03)$ \\
\hline \multirow[t]{2}{*}{ Common border } & & $11.64^{* * *}$ & $12.98^{* *}$ & & 4.81 & 1.48 \\
\hline & & $(4.43)$ & $(5.05)$ & & $(6.71)$ & $(6.74)$ \\
\hline \multirow[t]{2}{*}{ Common history } & & 2.69 & 1.24 & & 11.07 & 9.49 \\
\hline & & $(5.47)$ & $(5.59)$ & & $(7.54)$ & $(8.36)$ \\
\hline \multirow[t]{2}{*}{ Common language } & & $15.39^{* *}$ & -3.06 & & 11.38 & 5.74 \\
\hline & & $(6.52)$ & $(8.08)$ & & (12.19) & $(8.92)$ \\
\hline \multirow[t]{2}{*}{$\Delta$ VAT rate } & & $3.16^{* * *}$ & 0.41 & & 0.92 & -0.00 \\
\hline & & $(1.20)$ & (1.19) & & $(0.91)$ & $(1.15)$ \\
\hline Observations & 248 & 248 & 248 & 237 & 237 & 237 \\
\hline $\mathrm{R}^{2}$ & 0.18 & 0.25 & 0.59 & 0.11 & 0.16 & 0.44 \\
\hline Country FEs & & & $\checkmark$ & & & $\checkmark$ \\
\hline
\end{tabular}

Ordinary Least Square Regressions with heteroskedasticity robust standard errors. Dependent variables are country pair discrepancies as defined by Eq. 5. ***,**, and * indicate statistical significance levels for $p$-val $<0.01, p$-val $<0.05$ and $p$-val $<0.1$

The exporter records the cross-border transaction, while the importer-the final consumer-does not. When low-value transactions are performed on a high scale, statistics systematically under-report true import figures. This is a direct effect of socalled de-minimis thresholds. ${ }^{45}$ Thus, the combination of e-commerce and dis-intermediation is a growing challenge for statisticians, especially in the correct recording of services transactions.

At the same time, e-commerce has also become a platform for criminals who have set up digital VAT carousel schemes. In principle, the mechanism for VAT fraud in e-commerce functions in an analogous manner as in traditional goods trade: exports are VAT-exempt. Declaring services as exports which are in fact not exported therefore materializes in non-remitted value added tax. Borselli et al. (2015) describe a case disclosed in Italy, where two large telecommunication providers became unknowingly part of a cross-border VAT fraud scheme that cost Italian taxpayers $365 \mathrm{mn}$ Euro. This provides evidence that cross-border VAT fraud is not only limited to goods trade. Following up on this, VAT fraud might be even more profitable

\footnotetext{
${ }^{45}$ E.g., according to the German foreign trade legislation every transaction worth more than 12,500 Euro must be reported to the Bundesbank, who is in charge of compiling German services trade statistics. As a consequence, all payments below this threshold remain undocumented.
} 
in services trade due to lower transactions costs in case of the involvement of any physical shipment.

In the EU, statistical recording is hampered by a fundamental lack of harmonization. This is particularly true for the collection of cross-border services trade data. The existence of 28 different regimes in the EU not only causes statistical discrepancies; the poor data situation also makes it easier for fraudulent parties to hide their illegal activities. To avoid unlawful practices with respect to services trade, some EU Member States, e.g., Germany have partially changed their systems of VAT collection. In contrast to the general principle, in which the provider of a service is obliged to remit VAT, a reverse charging has been implemented. ${ }^{46}$ Basically, it levies the duty to remit VAT to the services recipient, e.g., the final consumer. In order to fight tax fraud, Borselli et al. (2015) also recommend reforms toward a system of reverse charging. The authors are unaware of solid empirical evaluations of such VAT reforms which ideally will be covered by future research based on micro data.

With respect to ongoing debates about the implementation of a revenue-based digital services tax (DST), an accurate revenue attribution to destination markets is a prerequisite. Thus, improving data quality on cross-border supply of services should be in the twofold interest of countries, i.e., to fight VAT fraud as well as for an accurate tax base for a potential future DST.

\subsection{Potential VAT revenue shortfalls}

In the following, we quantify VAT revenue shortfalls for EU Member States. Thereby, we assume that VAT fraud is the only reason for the observed credit-bias in intra-EU BoP accounts. Given this relatively strict assumption, our estimates should be interpreted as an upper bound of the actual fiscal loss. Note, however, that there may be VAT fraud that is not detectable in international trade statistics. Hence, our estimates may also underestimate cross-border VAT fraud.

Let $X_{i j}$ be the sum of services and goods exports of country $i$ to country $j$, and let $M_{j i}$ be the imports of country $j$ from $i$, where $i$ and $j$ are both members of the EU. Let the average VAT rate in country $j$ be $\bar{t}_{j}$. If the entire data discrepancy were due to VAT fraud, the fiscal loss to the government in country $j$ would amount to

$$
T_{j}=\bar{t}_{j} \sum_{i}\left(X_{i j}-M_{j i}\right)
$$

for all pairs $i j$ where $X_{i j}>M_{j i}$. For the EU as a whole, the aggregate loss yields

$$
T=\sum_{j} \sum_{i} \bar{t}_{j}\left(X_{i j}-M_{j i}\right)
$$

Our data do not allow calculating $T_{j}$ from Eq. 7, because $\sum_{i}\left(X_{i j}-M_{j i}\right)>0$ is only satisfied for $18 \mathrm{EU}$ Member States (as well as the Union as a whole). However, we know aggregate balances vis-à-vis the EU as a whole for all Member States (see

$\overline{46}$ German VAT Legislation, accessed on December 20, 2018. 
Sect. 2.3). Let $\bar{t}$ be the GDP weighted average EU VAT rate ${ }^{47}$, the EU-wide VAT loss can be approximated by

$$
T=\bar{t}\left(\sum_{j} \sum_{i}\left(X_{i j}-M_{j i}\right)\right) .
$$

Since $\sum_{j} \sum_{i}\left(X_{i j}-M_{j i}\right)=307$ bn Euro in 2018 , with $\bar{t}=0.21$, we arrive at about 64.5 bn Euro of taxes forfeited. As the UK's contribution to the discrepancies is most likely resulting from measurement error, not the full amount of 307 bn Euro is due to VAT fraud. But even within the Euro Area, the discrepancy of 126 bn Euro implies an amount of fraud equal to 26.5 bn Euro; more than 70 Euro per capita. Put differently, if we assume that VAT fraud affects trade in goods only, the fiscal loss amounts to 34.9 bn Euro. From 2006 to 2018, the cumulative self-surplus for goods of the entire EU amounts to 2,047 bn Euro. Assuming an average VAT rate of only $18 \%$ for the entire period ${ }^{48}$, EU budgets could have fallen short of 370 bn Euro over the past 13 years.

\subsection{Implementing an electronic clearing procedure}

Trade data appear massively distorted by inaccurate measurement and fraudulent misreporting. We believe in technical solutions to tackle both. Automated data exchange has effectively fought tax fraud in other areas, such as capital income, and could well be applied for a EU-wide VAT cooperation. An outline of such a solution could look as follows: the implementation of an electronic clearing procedure that documents all cross-border transactions for goods and services. Every transaction should require a two-factor authentication: first, the exporter reports export value, quantity, and counterparty to the system. Second, the importer confirms transaction details. The data collected would be automatically transmitted to statistical offices and tax authorities. The reverse VAT charging, that usually applies to intra-community supply, should apply here as well. As long as the importer does not confirm the transaction, VAT liability is with the exporter. At the moment of confirmation, tax liability passes over to the importer. In this system, to avoid having to remit VAT, the exporter would urge the importer to confirm the transaction. In any case, at least one party would have to remit VAT. Thus, potential fraud (mis-declaration or a wrong confirmation by any of the two parties) can no longer lead to non-taxation. Thereby, legal VAT evasion would at least be limited to the scale that VAT rates differ across EU Member States.

This system is also applicable for business-to-consumers services transactions: every EU citizen could have an electronic VAT ID to pay taxes for, e.g., imported streaming services or other e-commerce services. Payments could be processed automatically by an electronic VAT App. An additional advantage of this procedure is that de-minimis thresholds would become obsolete.

\footnotetext{
47 Source: Eurostat 2019. Using an average VAT rate can easily lead to an underestimation as the incentive for fraud increases in the VAT rate.

48 VAT rates have slightly increased over time.
} 


\section{Concluding remarks}

This paper reports and analyzes large inconsistencies in intra-European balance of payments data. The mere size of the mysterious EU trade surplus with itself -307 bn Euro, or $1.9 \%$ of the Union's GDP-is truly remarkable. This EU trade selfsurplus is persistent over time. Recently, the correct recording of services trade has become an additional challenge for statisticians due to the expansion of cross-border supply of services, e.g., by e-commerce traders and streaming or cloud services providers.

The EU self-surplus is equivalent to $86 \%$ of the global trade self-surplus of 422 bn USD in 2018. After the EU Eastern Enlargement in 2004, reported discrepancies have quadrupled. The trade self-surplus of the Euro Area amounts to only $41 \%$ of the EU self-surplus. Somewhat ironically, after the UK's departure from the EU, average data quality in the Union improves.

This paper introduces a simple measure for discrepancies on the country and country pair level. Our analysis finds large heterogeneity in data accuracy across countries indicating substantial differences in governmental practices of statistical recording. According to our estimations, Cyprus, Ireland, Luxembourg, and Sweden are the EU Member States with the most inaccurate statistical regime. The Netherlands provide the most accurate data for goods trade. Accounting for economic size, British figures seem to distort intra-EU current account data most strongly - an issue that is, at least formally, resolved by Brexit. The self-surpluses for goods and services trade have increased over time and give reason to suspect that statistical regimes in the EU are systematically incapable of tracking true import and export figures.

Applying forensic accounting methods, we find suggestive evidence that VAT fraud drives discrepancies, in particular for neighboring countries and countries with differentials in applied VAT rates. Attributing the observed discrepancies to VAT fraud, we can quantify EU-wide VAT revenue shortfalls from 27 to 35 bn Euro per year in a realistic scenario. At worst, revenue shortfalls would amount to 64 bn Euro. Finally, we link the growing importance of e-commerce and the process of dis-intermediation to rapidly growing discrepancies in services trade. For the sake of fighting tax fraud, but also to enable policy relevant research based on reliable data, we call on the institutions in charge to substantially improve quality and reliability of intra-EU BoP data. Therefore, we have outlined an electronic clearing procedure that has great potential to inhibit tax fraud and misreporting. With respect to services trade, the correct accounting of cross-border services supply would also be a prerequisite for a future digital services tax. Also, the non-disclosure or non-collection of certain BoP items (e.g., primary income) need to be tackled urgently.

This paper is also meant to encourage future research in the field of VAT/tax fraud, profit shifting, missing trade, and the ex-post evaluation of tax reforms, such as the introduction of reverse charging procedures. The use of micro data could complement the macro approach taken in this study.

Supplementary Information The online version contains supplementary material available at https://doi. org/10.1007/s10797-021-09713-x. 
Acknowledgements This paper is not meant to represent the positions or opinions of the WTO or its members, nor the official position of any WTO staff, and is without prejudice to members' rights and obligations under the WTO. All errors are our own. The authors thank Eva Jaus from the Eurostat Helpdesk for her patience when answering all our queries. Florentine Friedrich, formerly research intern at the Ifo Institute, deserves our gratitude for her excellence assistance at an early stage of this project. The authors are also grateful for comments and suggestions by two unknown referees.

Funding Open Access funding enabled and organized by Projekt DEAL.

Open Access This article is licensed under a Creative Commons Attribution 4.0 International License, which permits use, sharing, adaptation, distribution and reproduction in any medium or format, as long as you give appropriate credit to the original author(s) and the source, provide a link to the Creative Commons licence, and indicate if changes were made. The images or other third party material in this article are included in the article's Creative Commons licence, unless indicated otherwise in a credit line to the material. If material is not included in the article's Creative Commons licence and your intended use is not permitted by statutory regulation or exceeds the permitted use, you will need to obtain permission directly from the copyright holder. To view a copy of this licence, visit http://creativecommons.org/licen ses/by/4.0/.

\section{References}

Baines, T. S., Lightfoot, H. W., Benedettini, O., \& Kay, J. M. (2009). The servitization of manufacturing: A review of literature and reflection on future challenges. Journal of Manufacturing Technology Management, 20(5), 547-567.

Bonatti, L., \& Fracasso, A. (2013). the german model and the European crisis. Journal of Common Market Studies, 51(6), 1023-1039.

Borselli, F., Fedeli, S., \& Giuriato, L. (2015). Digital VAT carousel fraud: A new boundary for criminality? Tax Notes International, 77(8), 707.

Braml, M. T., \& Felbermayr, G. J. (2019). What do we really know about the transatlantic current account? CESifo Economic Studies, 65(3), 255-274.

Chesson, A., Marilyn, T., \& Haynes, J. (2018). Asymmetries in trade data: Diving deeper into UK bilateral trade data. Office for National Statistics.

Chimeli, A. B., \& Soares, R. R. (2017). The use of violence in illegal markets: Evidence from mahogany trade in the Brazilian amazon. American Economic Journal: Applied Economics, 9(4), 30-57.

Dimitrov, P. (2004). Differences between balance of payments and foreign trade statistics. Eurostat Working Papers and Studies 2.

Fearing, A., Hopes, J., Jaras, T., Adeniji-Adele, A., Brooks, I., Kandemir, I., Hristova, V., \& Whittle, E., \& Patel, K. (2015). Implementing the destination princple to intra-EU B2B supplies of goods. Final report TAXUD/2013/DE/319.

Fedeli, S. and Forte, F. (2009). Models of cross-border VAT fraud. University of Rome La Sapienza Working Paper, No. 123.

Feenstra, R. C., Hai, W., Woo, W. T., \& Yao, S. (1999). Discrepancies in international data: An application to China-Hong Kong Entrepôt trade. American Economic Review, 89(2), 338-343.

Felbermayr, G., Gröschl, J.K., \& Heiland, I. (2018). Undoing Europe in a new quantitative trade model. Ifo Working Paper Series, No. 250.

Ferrantino, M. J., Liu, X., \& Wang, Z. (2012). Evasion behaviors of exporters and importers: Evidence from the US-China trade data discrepancy. Journal of international Economics, 86(1), 141-157.

Fisman, R., \& Wei, S.-J. (2009). The smuggling of art, and the art of smuggling: Uncovering the illicit trade in cultural property and antiques. American Economic Journal: Applied Economics, 1(3), 82-96.

Frankel, J. (1978). Is there trade with other planets? International Monetary Fund.

Gros, D. (2012). Macroeconomic imbalances in the Euro area: Symptom or cause of the crisis? (p. 266). CEPS Policy Brief.

Gros, D. (2017). Is Germanys current account surplus bad for the world economy? CEPS Commentary. 
Helbling, T., \& Terrones, M. E. (2009). From deficit to surplus: Recent shifts in global current accounts. World Economic Outlook, 35-39.

International Monetary Fund (2009). BPM6. Balance of Payments and International Investment Position Manual, 6th Edition.

Kollmann, R., Ratto, M., Roeger, W., Vogel, L., et al. (2015). What drives the german current account? And how does it affect other EU member states? Economic Policy, 30(81), 47-93.

Krugman, P. (2010). The theory of interstellar trade. Economic Inquiry, 48(4), 1119-1123.

Mankiw, N.G. (2018). Surprising truths about trade deficits. The New York Times, page BU4. [Retrieved Jan 7, 2019].

Medina, L. \& Schneider, F. (2018). Shadow economies around the world: What did we learn over the last 20 years?, IMF Working Paper, No. 17.

Morrow, P., Smart, M., \& Swistak, A. (2019). VAT compliance, trade, and institutions. CESifo Working Paper, No. 7780.

Vézina, P.-L. (2015). Illegal trade in natural resources: Evidence from missing exports. International Economics, 142, 152-160.

Publisher's Note Springer Nature remains neutral with regard to jurisdictional claims in published maps and institutional affiliations. 